Oral Section

\title{
Investigating homeopathic preparations with light spectroscopy
}

\author{
Sabine Klein, Annegret Sandig, Stephan Baumgartner, Ursula Wolf \\ Institute of Complementary Medicine KIKOM, University of Bern, Bern, Switzerland
}

\begin{abstract}
Background: Several series of experiments from our research group have shown ultraviolet (UV) light transmission of homeopathic preparations to slightly but significantly differ from controls. We now investigated whether visible and near infrared spectroscopy were also useful for exploring properties of homeopathic preparations.

Materials and methods: Homeopathic preparations of copper sulfate $\left(\mathrm{CuSO}_{4}\right)$, hypericum and sulfur $\left(\mathrm{S}_{8}\right)$ were produced in 30 sequential steps of 1:100 dilutions (c-preparations). As controls, succussed potentization medium was used. Transmission of the samples from 190-1100nm was measured 4 times on 5 days with a double beam Shimadzu UV PC 1601 spectrophotometer. To correct for the daily variations of the spectrophotometer, transmission of the samples at each $\mathrm{nm}$ was divided by the average transmission of the controls. Median transmissions of the samples were calculated for the ranges of 190-340nm (near and middle UV), 340-640nm (visible light without red), and 640-1100nm (red and near infrared). Differences in the median transmission between potency levels from $6 \mathrm{c}$ to $30 \mathrm{c}$ were determined using Kruskal-Wallis and Jonckheere-Terpstra tests.
\end{abstract}

Results: Differences in transmissions of the various potency levels were more pronounced in the UV range than in the visible or red/near infrared range. The Kruskal-Wallis test revealed significant differences for homeopathic preparations of $\mathrm{CuSO}_{4}$, hypericum and $\mathrm{S}_{8}$ in the $\mathrm{UV}$ range $(\mathrm{p}=0.032,0.008,0.009$, respectively) and of $\mathrm{S}_{8}$ in the visible range $(\mathrm{p}=0.026)$. Jonckheere's test showed a tendency towards ascending medians with ascending potency levels for $\mathrm{CuSO}_{4}$ in the UV range ( $\left.\mathrm{p}=0.080\right)$. Significant trends were revealed for hypericum in the visible range $\left(p=0.042\right.$, descending medians) and $S_{8}$ in the UV range $(p=0.015$, ascending medians).

Conclusion: UV spectroscopy seemed to be more suitable for investigating homeopathic preparations than visible or near infrared spectroscopy, since differences in transmission were more pronounced in the UV range.

Keywords: homeopathy, anthroposophically extended medicine, spectroscopy, optical properties, hypericum, dilution

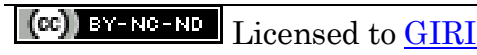

Support: The work was supported by the Karl and Veronica Carstens-Foundation to purchase high quality glass ware. The KVC Foundation had no whatsoever influence on the study.

Conflict of interest: The authors declare there is no conflict of interest

Received: 01 June 2012; Revised: 07 August 2012; Published: 30 September 2012.

Correspondence author: Ursula Wolf, ursula.wolf@kikom.unibe.ch

How to cite this article: Klein SD, Sandig A, Baumgartner S, Wolf U. Investigating homeopathic preparations with light spectroscopy. Int J High Dilution Res [online]. 2012 [cited YYYY Month dd]; 11(40):117-117. Proceedings of the XXVI GIRI Symposium; $2012 \quad$ Sep 20-22; Florence (Italy). GIRI; 2012; Available from: http://www.feg.unesp.br/ ojs/index.php/ijhdr/article/view/584/571 